Journal of Physical Science, Vol. 28(1), 15-26, 2017

\title{
Microwave Dielectric Properties of Four Types of Rhizomes from Zingiberaceace Family
}

\author{
Nor Azila Abd. Aziz, ${ }^{1 *}$ Jumiah Hassan, ${ }^{1,2}$ Zulkifly Abbas ${ }^{1}$ \\ and Nurul Huda Osman ${ }^{1}$ \\ ${ }^{1}$ Department of Physics, Faculty of Science, Universiti Putra Malaysia, \\ 43400 UPM Serdang, Selangor, Malaysia \\ ${ }^{2}$ Institute of Advanced Technology (ITMA), Universiti Putra Malaysia, \\ 43400 UPM Serdang, Selangor, Malaysia
}

*Corresponding author: azila_aziz87@yahoo.com

Published online: 15 April 2017

To cite this article: Abd. Aziz, N. A. et al. (2017). Microwave dielectric properties of four types of rhizomes from Zingiberaceace family. J. Phys. Sci., 28(1), 15-26, https://doi.org/10.21315/jps2017.28.1.2

To link to this article: https://doi.org/10.21315/jps2017.28.1.2

\begin{abstract}
The dielectric properties of four types of rhizomes from Zingiberaceace families, namely Java turmeric, Mango ginger, Black turmeric and Turmeric were measured. The non-destructive measurement technique was adopted for the measurement using HP-85070B open-ended coaxial line probe coupled with a computer-controlled Automated Network Analyzer (ANA) at the frequency range of 0.13-20 GHz which is in the microwave frequency region. The dielectric properties of all samples are presented graphically to show the dependence of these properties on moisture content and frequency. The results show that the dielectric properties of samples follow the trend of dielectric properties of deionised water. The dielectric constant decreased with increase in frequency and the dielectric loss factor decreased in low frequency before increasing at $1.5 \mathrm{GHz}$ and above. The penetration depths for all samples were calculated. The results show that they were only dependent upon the moisture at low frequency $(\leq 10 \mathrm{GHz})$.
\end{abstract}

Keywords: Moisture content, dielectric properties, penetration depth, types of rhizomes, Zingiberaceace family

\section{INTRODUCTION}

Dielectric properties of materials are the electrical characteristics of poorly conducting materials, as opposed to other materials such as metals that are generally

(C) Penerbit Universiti Sains Malaysia, 2017 
good electrical conductors. ${ }^{1}$ It is very important to determine their interaction with the electric fields. In the processes involving radio frequency (RF) or microwave dielectric heating, it can be determined how well energy can be absorbed and how rapidly a material can be heated. ${ }^{2}$ The relation between interactions of microwaves with materials are described through the complex relative permittivity of the material. It is mathematically expressed as in Equation 1:

$$
\varepsilon^{*}=\varepsilon^{\prime}-j \varepsilon^{\prime \prime}
$$

where $\varepsilon^{\prime}$ is the dielectric constant, which is the ability of a material to store electromagnetic radiation, and $\varepsilon^{\prime \prime}$ the dielectric loss factor, which is the ability of material to dissipate electrical energy into heat. Often, the tangent of the loss angle $\tan \delta$ is used, i.e., $\tan \delta=\varepsilon^{\prime \prime} / \varepsilon^{\prime}$. The conductivity of the dielectric is also used, $\sigma=\omega \varepsilon_{o} \varepsilon^{\prime \prime} \mathrm{S} / \mathrm{m}$, where $\varepsilon_{o}$ is the permittivity of free space, $8.854 \times 10^{-12} \mathrm{~F} / \mathrm{m}$, and $\omega=2 \pi f$, where $f$ is frequency in Hertz.

Dielectric properties of materials, especially food and agricultural products can be influenced by many factors such as moisture content, temperature, frequency of the alternating fields applied during the measurement, density, composition and structure of the materials. As the food materials and agricultural products are hygroscopic material, the amount of water in the material is a dominant factor. The chemical composition of materials with the presence of mobile ions and the permanent dipole moments can also influence the dielectric properties of material, and water is the best example. ${ }^{2}$

The dielectric properties of food materials and agricultural products have been investigated for a long time. The dielectric properties of Marc grape have been measured as a function of temperature and moisture content. As expected, the moisture content affects the dielectric properties for all samples, but temperature was not shown to have a clear influence in both dielectric properties due to the presence of salt in the Marc grape. ${ }^{3}$ The maturity effects on the dielectric properties of apples from 10 to $4500 \mathrm{MHz}$ have been studied. It is shown that no obvious correlations are found between permittivity and firmness, moisture content or $\mathrm{pH} .{ }^{4}$

Determination of dielectric properties of corn seeds from 1 to $100 \mathrm{MHz}$ has been performed and the results show that the moisture content is the most significant factor affecting the dielectric properties of corn seed. The dielectric properties increased with the increasing moisture content and bulk density. ${ }^{5}$ The analysis of bread dielectric properties has been investigated by using the combination of mixture equation method and open-ended coaxial probe. Influences of frequency, moisture content and temperature on bread dielectric properties were analysed and 
from the result, the penetrations of both RF and microwave energies decrease with the increasing temperature and moisture content. ${ }^{6}$ It is very valuable to know the dielectric properties as it is used to predict the heating rates, estimate temperature for storage to maintain quality of product, and develop improved moisture meter and many other applications.

This paper presents the dielectric properties for four types of rhizomes from Zingiberaceace family, namely Java turmeric (Curcuma xanthorrhiza Roxb.), Mango ginger (Curcuma amada), Black turmeric (Curcuma aeruginosa Roxb.), and Turmeric (Curcuma longa) in the frequency range between 0.13 and $20 \mathrm{GHz}$ at various evaporated moistures. A non-destructive measurement technique using a combination of the HP-85070B open-ended coaxial line probe with a computer controlled Automated Network Analyzer (ANA) were used. This equipment produced a fast measurement technique and the sample used for measurement can be used for another measurement.

\section{EXPERIMENTAL}

\subsection{Sample Preparation}

Fresh samples bought from the wet market were stored at $4^{\circ} \mathrm{C}$ in a refrigerator to maintain the freshness. Their skin was removed and ground. The samples were put on the plate dish where each dish consisted about $10 \pm 0.001 \mathrm{~g}$ of the sample. To obtain different moisture contents, the samples were put in the oven at different temperatures $\left(26^{\circ} \mathrm{C}\right.$ to $\left.90^{\circ} \mathrm{C}\right)$ where the times of drying were fixed at $24 \mathrm{~h}$. To ensure the moisture content was at the uniform situation as well as to cool down the temperature of the sample to $26^{\circ} \mathrm{C}$, the samples were placed in desiccators containing silica gels for about 5 to $10 \mathrm{~min}$. The samples were weighed using an electronic balance $( \pm 0.001 \mathrm{~g})$.

\subsection{Dielectric Properties Measurement}

The evaporated moisture of samples which were dried at different temperatures $\left(26^{\circ} \mathrm{C}\right.$ to $\left.90^{\circ} \mathrm{C}\right)$ was calculated. Figure 1 and 2 show the set up for dielectric measurement and how the measurement was done. The dielectric properties of samples were measured using the HP $85070 \mathrm{~B}$ open-ended coaxial line probe (OECP) coupled with a computer-controlled ANA at frequencies 0.13 to $20 \mathrm{GHz}$. The instrument was first calibrated using three different loads: (1) air, (2) metallic short block and (3) distilled water at room temperature $\left(26^{\circ} \mathrm{C}\right)$. After calibration, the measurements of the dielectric properties of the sample were taken. The sample 
were placed in special containers and pressed carefully to ensure no air gap occur. All the measurements were conducted by placing the flat face of the open-ended probe on the surface of the samples. Measurements were taken at least three times for each sample in order to avoid erroneous values caused by the presence of air. The probe and the samples should have a good contact during the measurements.

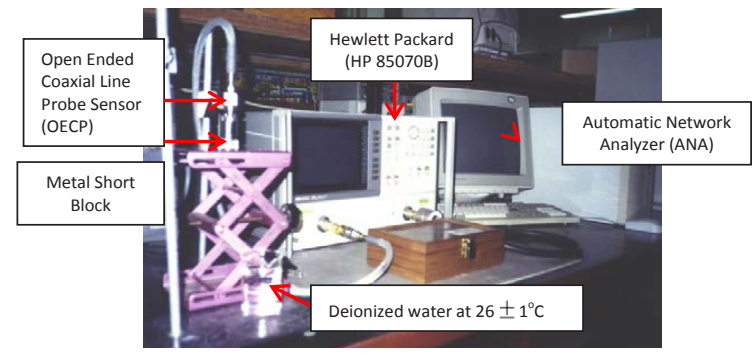

Figure 1: Open-ended coaxial line probe sensor coupled with ANA for dielectric properties measurement.

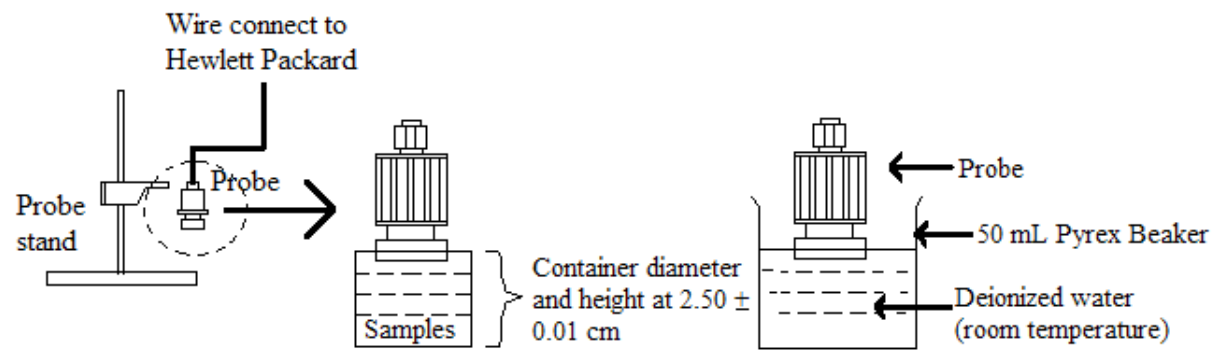

Figure 2: Illustrated figure on the measurement of water, dry and fresh sample.

\section{RESULTS AND DISCUSSION}

The evaporated moisture of four types of rhizomes from Zingiberaceace family as a function of drying temperatures is shown in Figure 3. The optimum temperature in determining the moisture content of Java turmeric, Mango ginger, Black turmeric and Turmeric is different. For Java turmeric, the optimum temperature is assumed to be at $90^{\circ} \mathrm{C}$ with $E M_{J}$ estimated at $86.79 \%$; for Mango ginger it is at $50^{\circ} \mathrm{C}$ with $E M_{M}$ estimated at $87.23 \%$; for Black turmeric it is at $60^{\circ} \mathrm{C}$ with $E M_{B}$ estimated at $84.23 \%$; and Turmeric is assumed to be at $70^{\circ} \mathrm{C}$ with $E M_{T}$ estimated at $79.62 \%$. The optimum temperature was chosen according to the highest values of $E M_{f s}$, during which the moisture is fully evaporated. 


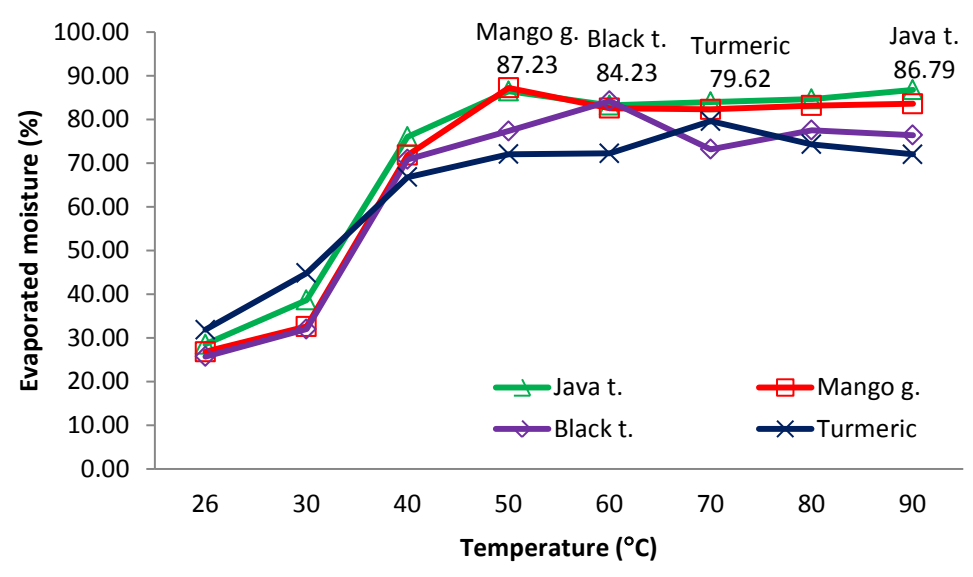

Figure 3: Evaporated moisture (EMfs) of four types of rhizomes from Zingiberaceace family at various drying temperature.

The dielectric constants of the four types of rhizomes is shown in Figure 4 with dielectric constant of water as a reference. Theoretically, the water is the main contributor to the dielectric constant and this was proven with the results shown where the values of dielectric constant are below that of water. ${ }^{7}$ Since there is less moisture or water polarised on the samples dried at $50^{\circ} \mathrm{C}$ and above, the dielectric constant remains almost constant. The dielectric properties of water and sample dried at temperature $26^{\circ} \mathrm{C}, 30^{\circ} \mathrm{C}$ and $40^{\circ} \mathrm{C}$ decrease as the frequency increase. This happens because of the movement of water dipoles called polarisation. As the frequency increased, dipole polarisation would start to die out or not able to follow the changing electromagnetic field and resulting dielectric constant approaches one at infinity of frequency.

The dielectric loss factor of the samples are shown in Figure 4 with dielectric loss factor of water as a reference. At low frequency, the dielectric loss factor decreased, but it started increasing at $1.5 \mathrm{GHz}$ and above following the trend of the deionised water. The decreasing of dielectric loss factor is due to the existence of ionic species in samples where the ionic interaction is predominantly at low frequency. At frequencies above $1.5 \mathrm{GHz}$, the dipole polarisation is the predominant mechanism, resulting in increase in dielectric loss factor. 


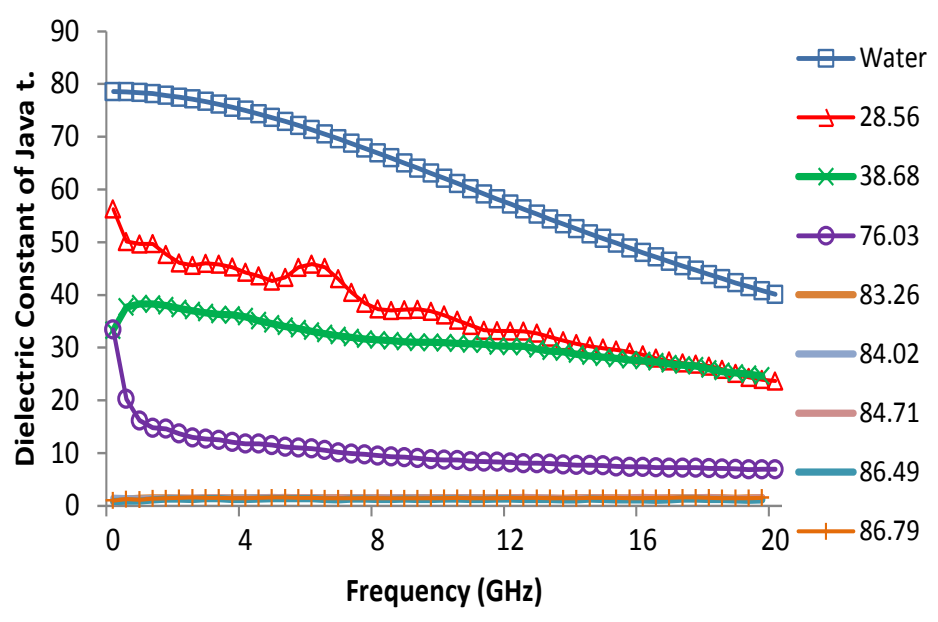

(a)

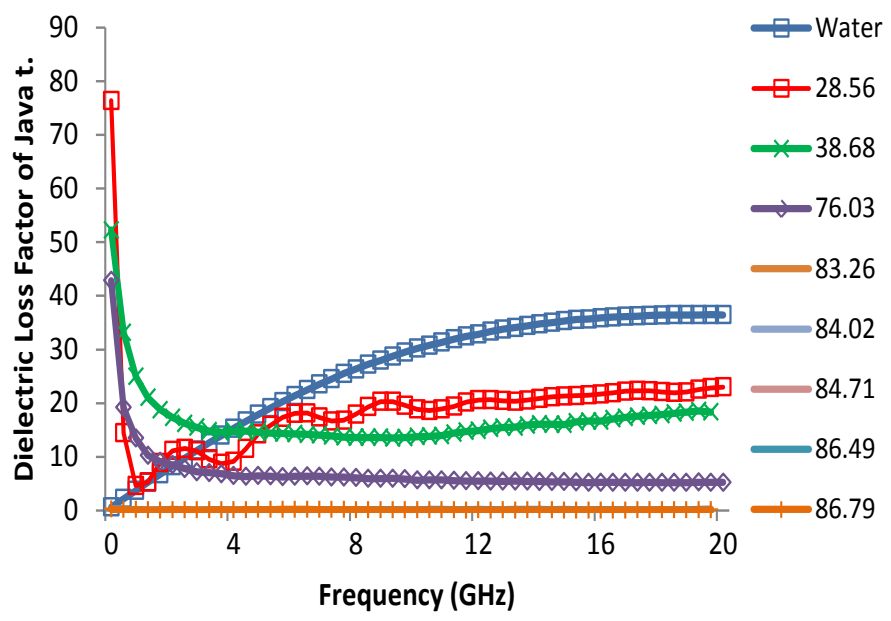

(b)

Figure 4: The dielectric properties of Java turmeric ( $a$ and b), Mango ginger (c and d), Black turmeric (e and $\mathrm{f}$ ), and Turmeric ( $\mathrm{g}$ and $\mathrm{h}$ ) as a function of frequency with respect to the evaporated moisture. (continued on next page) 


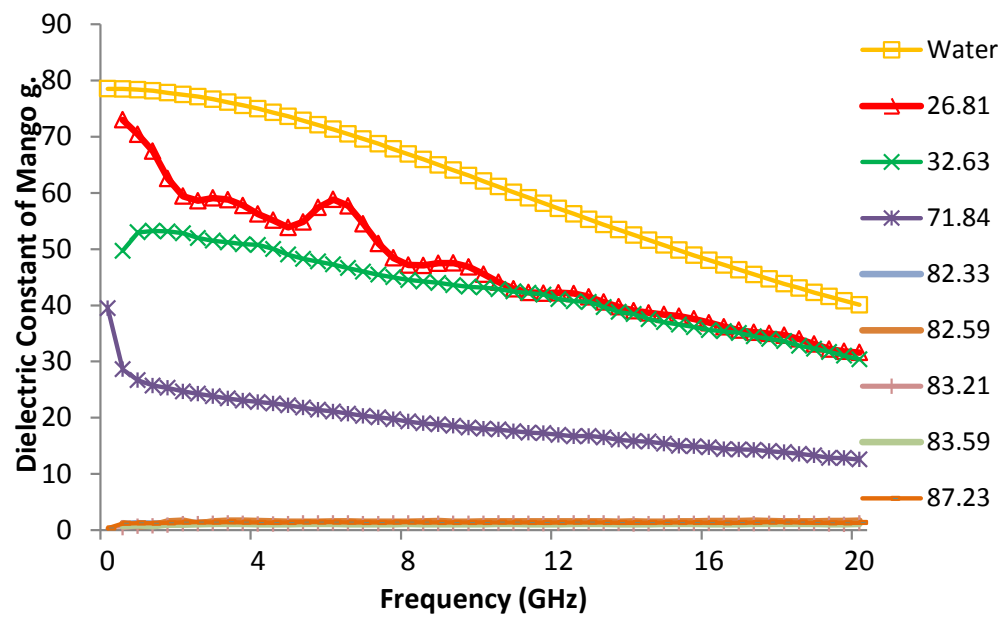

(c)

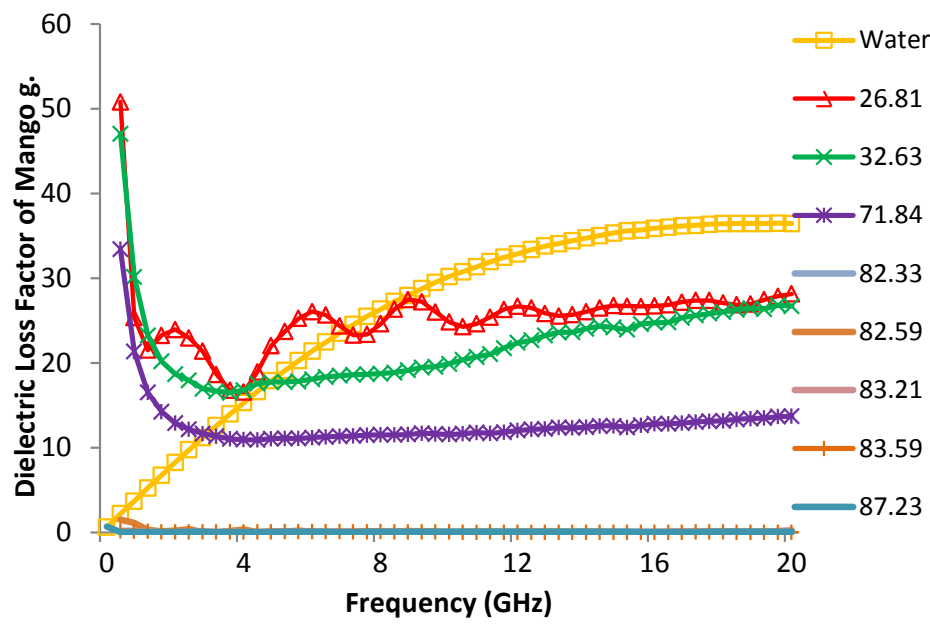

(d)

Figure 4: (continued) 


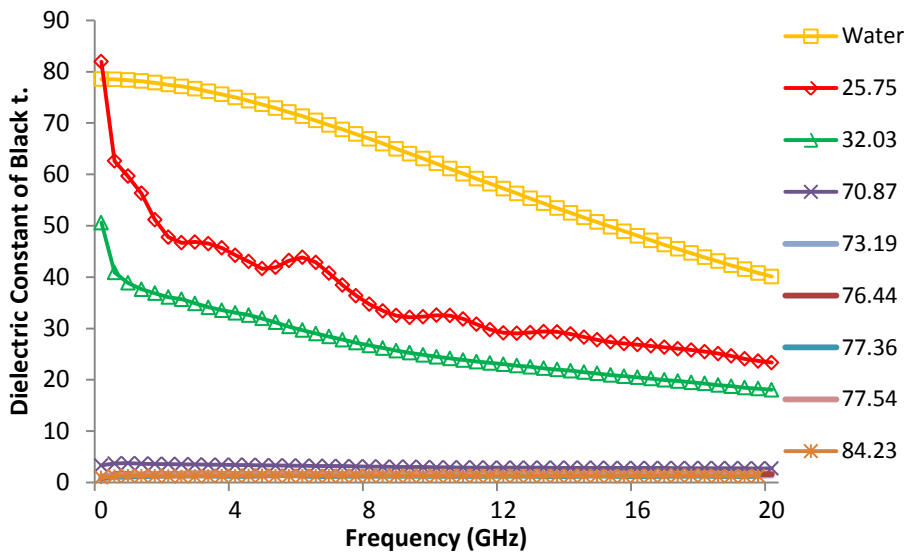

(e)

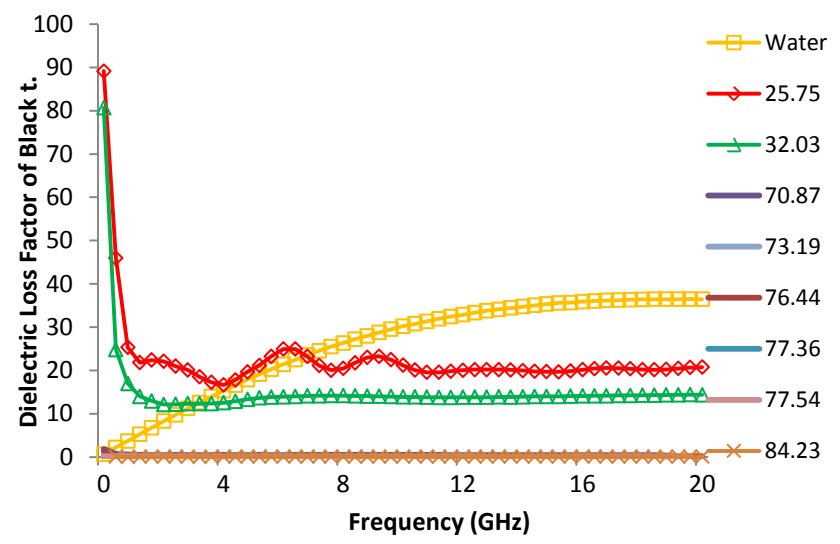

(f)

Figure 4: (continued) 


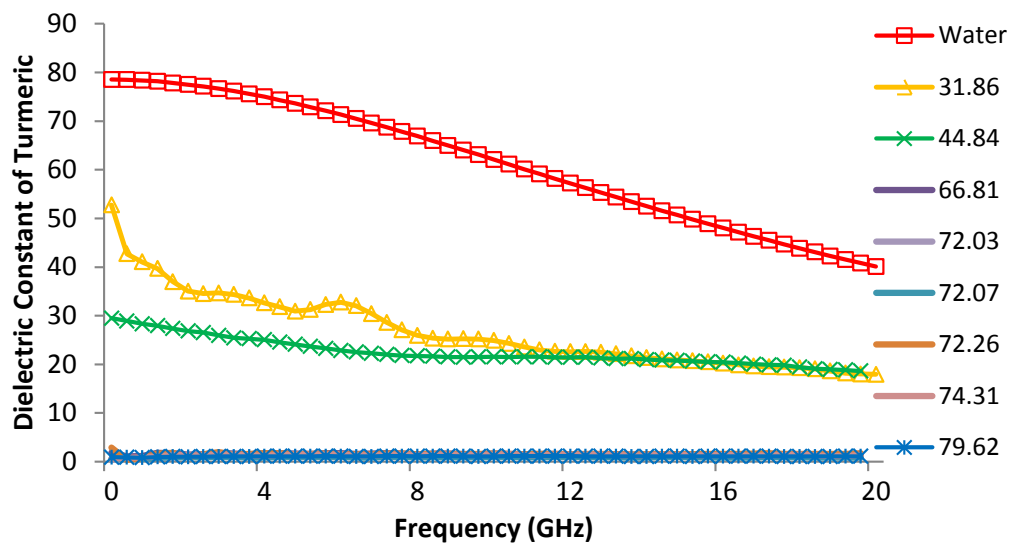

(g)

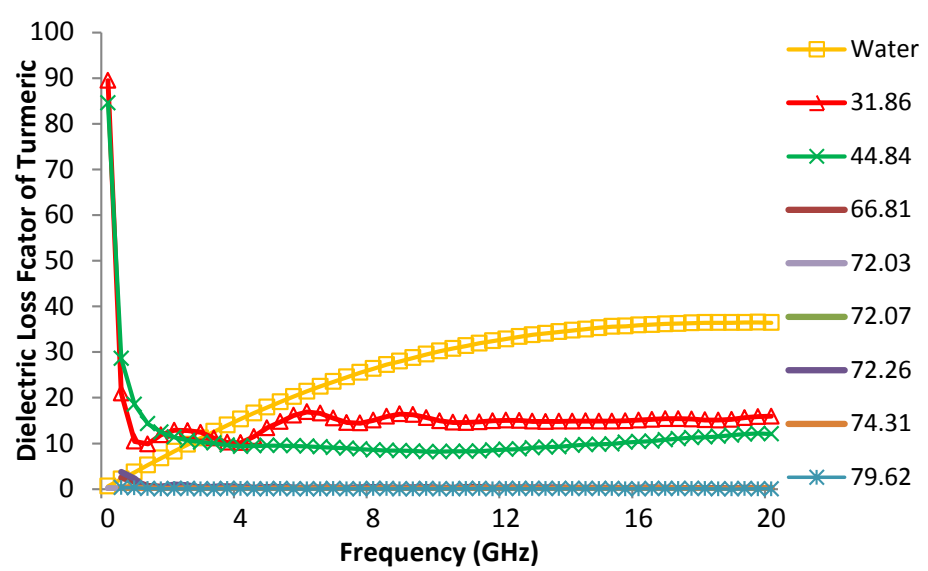

(h)

Figure 4: (continued)

\subsection{Penetration Depth}

The penetration depth is the distance over which the power intensity of electromagnetic waves is reduced to $36.79 \%$ of the original level. ${ }^{6}$ The penetration depth will influence the uniformity of microwave heating. As the penetration depth increased, the uniformity of microwave heating would increase too. According the Equation 2 below, the penetration depth is inversely proportional to frequency.

$$
D_{p}=\frac{\lambda_{o}}{2 \pi\left(\varepsilon^{\prime}\right)^{0.5}}\left[\left\{1+\left(\varepsilon^{\prime \prime} / \varepsilon^{\prime}\right)^{2}\right\}^{0.5}-1\right]^{-0.5}
$$


where $D_{p}$ is the penetration depth $(\mathrm{cm}), \lambda_{o}$ is the wavelength of the frequency used.

From the Figure 5, the result of penetration depth showed that it is affected by moisture at low frequency $(\leq 10 \mathrm{GHz})$. It is vice versa at high frequency $(\geq 10 \mathrm{GHz})$ where it is independently with moisture. From the result, the sample is assumed should be at low moisture content with a low operating frequency of microwave heating to get the uniform heating when using the microwave heating.

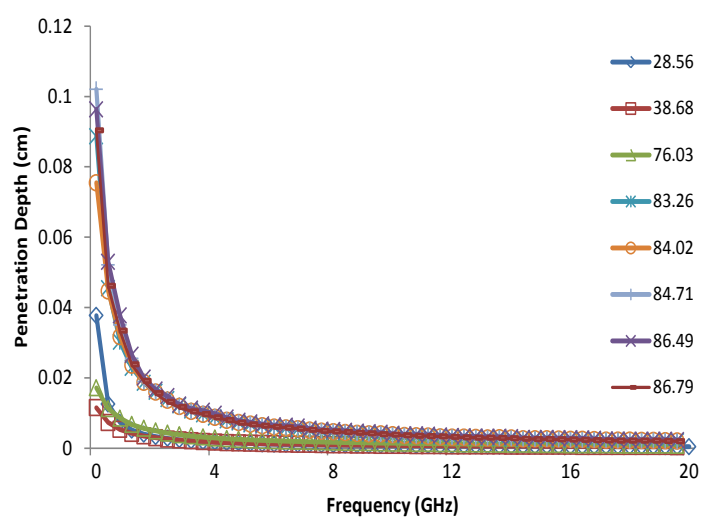

(a)

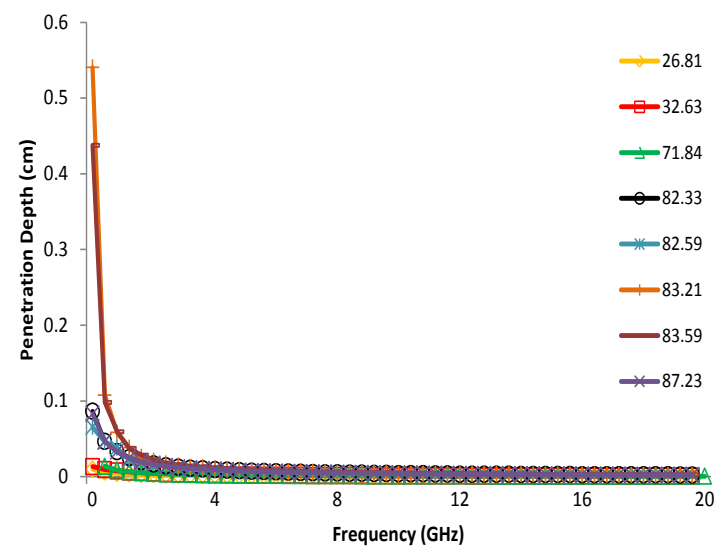

(b)

Figure 5: The penetration depth of Java turmeric (a), Mango ginger (b), Black turmeric (c), and Turmeric (d) as a function of frequency with respect to the evaporated moisture. (continued on next page) 


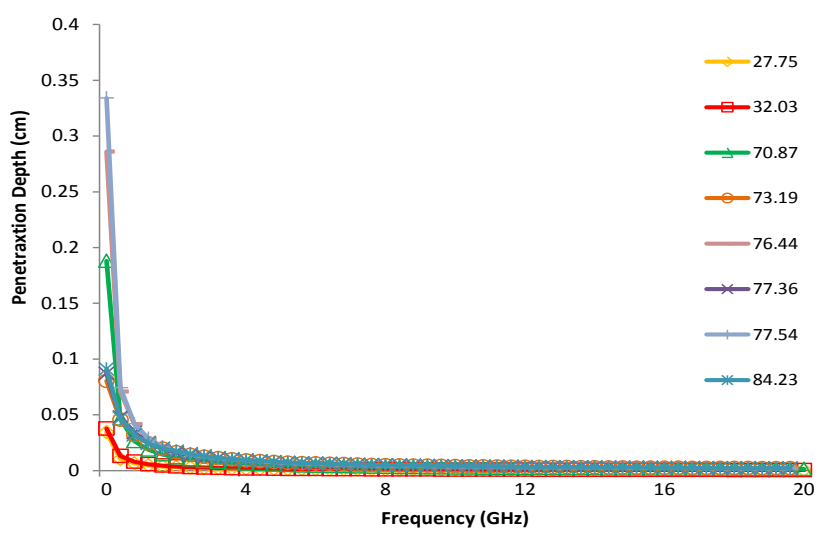

(c)

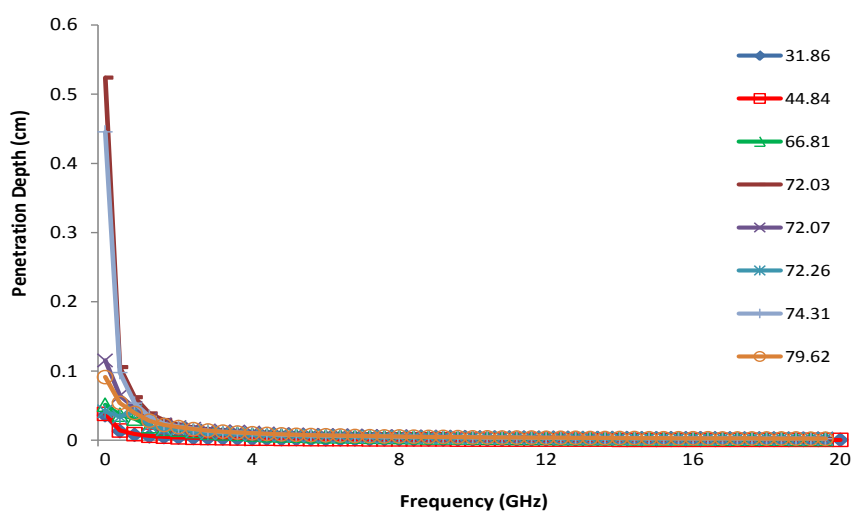

(d)

Figure 5: (continued).

\section{CONCLUSION}

The dielectric properties of four types of rhizomes from Zingiberaceace family have been successfully analysed and it has been shown to follow the trend of the deionised water. The dielectric constant is inversely proportional to frequency and at infinity, the dielectric constant approaches one as the polarisation died out. The dielectric loss factor decreased below $1.5 \mathrm{GHz}$ due to ionisation losses while it started to increase at $1.5 \mathrm{GHz}$ and above because of the bipolar polarisation. The penetration depth depends on frequency and moisture content. 


\section{ACKNOWLEDGMENTS}

The authors thank Ministry of Higher Education Malaysia for the financial support through the MyPhD and the Department of Physics, Faculty of Science, Universiti Putra Malaysia.

\section{REFERENCES}

1. Nelson, S. O. (2010). Fundamentals of dielectric properties measurements and agricultural applications. J. Microw. Power Electrom. Energy, 44(2), 98-113, https://doi.org/10.1080/08327823.2010.11689778.

2. Nelson, S. O. \& Trabelsi, S. (2012). Factors influencing the dielectric properties of agricultural and food products. J. Microw. Power Electrom. Energy, 46(2), 93-107, https://doi.org/10.1080/08327823.2012.11689828.

3. Sólyom, K. et al. (2013). Dielectric properties of grape Marc: Effect of temperature, moisture content and sample preparation method. J. Food Eng., 119(1), 33-39, https://doi.org/10.1016/j.jfoodeng.2013.05.005.

4. Guo, W. et al. (2011). Maturity effects on dielectric properties of apples from 10 to $4500 \mathrm{MHz}$. LWT Food Sci. Technol., 44(1), 224-230, https://doi. org/10.1016/j.lwt.2010.05.032

5. Sacilik, K. \& Colak, A. (2010). Determination of dielectric properties of corn seeds from 1 to $100 \mathrm{MHz}$. Powder Technol., 203(2), 365-370, https:// doi.org/10.1016/j.powtec.2010.05.031.

6. Liu, Y., Tang, J. \& Mao, Z. (2009). Analysis of bread dielectric properties using mixture equations. J. Food Eng., 93(1), 72-79, https://doi.org/10.1016/j. jfoodeng.2008.12.032.

7. Wang, S. et al. (2003). Dielectric properties of fruits and insect pests as related to radio frequency and microwave treatments. Biosyst. Eng., 85, 201-212, https://doi.org/10.1016/S1537-5110(03)00042-4. 